\title{
Synthesis and characterization of furfural-functionalized poly(vinyl alcohol) cross-linked with maleimide bearing tributyltin groups
}

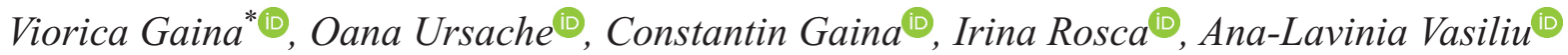 \\ Petru Poni Institute of Macromolecular Chemistry, 41 Gr.Ghica Voda Alley, RO-700487 Iasi, Romania
}

Received 16 July 2021; accepted in revised form 27 September 2021

\begin{abstract}
In the present work, new cross-linked networks based on furfural-functionalized poly(vinyl alcohol) (PVF) and maleimide compounds containing tributyltin groups were synthesized. The networks were obtained both as films and porous membranes. The structure of the compounds was confirmed by ATR-FTIR spectroscopy, and the morphology of the films $/ \mathrm{mi}$ croporous membranes was investigated using scanning electron microscopy measurements (SEM), the differences between the films and membranes being evidenced. The mechanical performance and thermal stability of the membranes were examined by dynamic mechanical analysis (DMA) and thermogravimetry analysis (TGA), respectively. In addition, their water absorption and antimicrobial properties were thoroughly discussed. The antimicrobial activity of furfural-functionalized poly(vinyl alcohol) was significantly improved by its reaction with compounds containing tributyltin groups.
\end{abstract}

Keywords: furfural-functionalized poly(vinyl alcohol), maleimides, tributyltin compounds, polymer membranes, antimicrobial activity

\section{Introduction}

Poly(vinyl alcohol) (PVA) is a semicrystalline, watersoluble, non-toxic, biocompatible, and biodegradable synthetic polymer with a great capability of forming films and fibers. It has excellent chemical resistance and good mechanical properties, and its utilization has grown steadily in recent years $[1,2]$. These properties of PVA have led to its use in a variety of industry areas, including chemical engineering, pharmaceutics, textiles, medical devices, and food additives [1-3]. The inherent hydrophilicity of PVA makes it an attractive polymer for water treatment applications in the form of membranes. Because of its highly hydrophilic nature, PVA must be modified to minimize swelling in water when fabricated for aqueous applications. Some different modification methods such as cross-linking, blending with other polymers, or incorporating various fillers into the PVA matrix have been used by researchers to reduce the swelling effects and improve the PVA membrane properties [4].

Several cross-linking methods have been published for different uses since, as a rule, all multifunctional compounds capable of reacting with hydroxyl groups can be used. PVA may be cross-linked by using multifunctional compounds such as dialdehydes $[5,6]$, dicarboxylic acids [7, 8], dianhydrides [9, 10], diisocyanates [11], inorganic compounds (boric acid, graphene oxide) $[12,13]$, etc. to inverse membrane selectivity and increase stability in aqueous solutions. Thus, PVA has been used to fabricate membranes for separation processes such as ultrafiltration [14-16], micro- and nanofiltration [17], reverse osmosis [18, 19], pervaporation [20-23]. In our previous work, we studied the functionalization of PVA by acetalization with compounds containing aldehyde 
groups and cross-linked by Diels-Alder reactions with bismaleimides or maleimide compounds having triethoxysilane groups [24-27]. Organic tin carboxylates have versatile molecular structures and potential biological properties such as antibacterial, antifungal, antitumor, cytotoxic, antiproliferative, anti-tuberculosis, and antidiabetic [28].

In this contribution, we have used tributyltin-(2,5dioxo-2,5-dihydro-1H-pyrrol-1yl)acetate, tributyltin 4-(2,5-dioxo-2,5-dihydro-1H-pyrrol-2-yl)benzoate and tributyltin-1-[3,5-bis(2,5- dioxo-2,5-dihydro1H-pyrrol-1-yl)benzoate to obtain porous membranes or films depending on the method used.

\section{Materials and methods}

\subsection{Reagents and materials}

PVA, white crystalline powder (average molecular weight of $77000-79000 \mathrm{~g} / \mathrm{mol}$, hydrolysis degree of 98\%), 2-furaldehyde, $99 \%$, dimethylsulfoxide (DMSO), $p$-toluene sulfonic acid ( $p$-TSA), 4-aminobenzoic acid, 3,5-diaminobenzoic acid, glycine (2-aminoacetic acid), acetic anhydride (SigmaAldrich, Darmstadt, Germany), bis(tributyltin oxide) (TBTO, Merck, Darmstadt, Germany) were used as received.

Furfural-functionalized poly(vinyl alcohol) (PVF) was prepared by acetalization of PVA in DMSO in the presence of $p$-TSA according to a previously reported method [24, 25]. The acetalization degree was 25\%. 4-Maleimidobenzoic acid, tributyltin (2,5-dioxo2,5-dihydro-1H-pyrrol-1-yl)acetate and tributyltin 4-(2,5-dioxo-2,5-dihydro-1H-pyrrol-1-yl)benzoate were prepared according to the method described in the literature $[29,30]$.

Tributyltin 1-[3,5-bis(2,5-dioxo-2,5-dihydro-1Hpyrrol-1-yl)]benzoate, 3 was prepared by the condensation reaction of 3,5-bismaleimidobenzoic acid with TBTO in toluene at reflux. 3,5-Bismaleimidobenzoic acid was prepared by the reaction of 3,5-diaminobenzoic acid $(1.52 \mathrm{~g}, 10 \mathrm{mmol})$ with maleic anhydride (1,96 g, $20 \mathrm{mmol})$ in acetic acid at reflux according to the method described in the literature [31]. This compound decomposed at its melting point of $253-255^{\circ} \mathrm{C}$.

3,5-Bismaleimido-benzoyl chloride was prepared from 3,5-maleimide benzoic acid $12.5 \mathrm{~g}(4 \mathrm{mmol})$ in $150 \mathrm{ml}$ DCE and 6 moles of thionyl chloride; the mixture was stirred at room temperature for $15 \mathrm{~min}$ and then refluxed for $3 \mathrm{~h}$. The excess of thionyl chloride was removed by distillation, and 3,5-bismaleimidobenzoyl chloride ( $10 \mathrm{~g}$ ) was obtained by crystallization and filtration of crystals.

FTIR $\left(\mathrm{KBr}, \mathrm{cm}^{-1}\right)$ : 1775 (CO-Cl), 1782, 1738 (imide I), 1410 (imide II), 1132 (imide III), 710 (imide IV), 1630 (maleimide $\mathrm{C}=\mathrm{C}$ ).

${ }^{1} \mathrm{H}-\mathrm{NMR}\left(\mathrm{CDCl}_{3}\right) \delta: 8.03(\mathrm{~m}, 2 \mathrm{H}$, aromatic CO, 7.42 (s, $1 \mathrm{H}$, other aromatic), 6.78 (m, 4H, olefinic).

\subsection{Membranes and films preparation $M(2,4)$ films}

A mixture of PVF and MI/BMI (furyl group: maleimide group =1:1) was dissolved in DMF $(10 \mathrm{ml})$ and stirred at $80-90^{\circ} \mathrm{C}$ for $4 \mathrm{~h}$. The reaction solution was degassed in a vacuum and quickly transferred to a glass plate using a doctor blade $(e=1 \mathrm{~mm})$. The solvent was evaporated in air at $80-90^{\circ} \mathrm{C}$ for $24 \mathrm{~h}$. The film was removed from the glass plate by soaking in cold water.

\section{$M(1,3,5)$ microporous membranes}

To a solution of PVF $(2 \mathrm{~g})$ dissolved in DMSO $(20 \mathrm{ml})$, maleimide/bismaleimide (furyl group: maleimide group $=1: 1)$ in DMSO $(10 \mathrm{ml})$ was added and stirred at $60^{\circ} \mathrm{C}$ for $30 \mathrm{~min}$, then distilled water $(2 \mathrm{ml})$ was added, and the solution was degassed and cast onto glass plates. The casting solution was put in an oven at $80^{\circ} \mathrm{C}$ for $30 \mathrm{~min}$. After cooling to room temperature, the glass plate was immersed in a bath of distilled water for $3 \mathrm{~h}$. The resulted membranes were washed with distilled water, then immersed overnight in a water bath, after which they were removed and dried at $60^{\circ} \mathrm{C}$ for $24 \mathrm{~h}$ and under vacuum. M5 stands for the PVF microporous membrane.

\subsection{Measurements}

The Fourier transform infrared (FTIR) spectra were recorded on a Bruker Vertex 70 (Ettlingen, Germany) instrument equipped with a Golden Gate single reflection ATR accessory, spectrum range 600$4000 \mathrm{~cm}^{-1}$.

Thermogravimetric measurements were conducted on an STA 449 F1 Jupiter device (Netzsch, Germany). Around $10 \mathrm{mg}$ of each sample was heated in alumina crucibles at a heating rate of $10^{\circ} \mathrm{C} / \mathrm{min}$. Nitrogen was used as an inert atmosphere at a flow rate of $50 \mathrm{ml} / \mathrm{min}$.

Dynamic mechanical experiments were made using a Diamond Perkin Elmer instrument (Singapore) that 
applies sinusoidal stress to the sample and measures the resulting strain. The force amplitude used was well within the linear viscoelastic range for all investigated samples. The thermo-mechanical properties were evaluated, starting from $-100^{\circ} \mathrm{C}$ up to beyond the glass transition temperature, at a heating rate of $4{ }^{\circ} \mathrm{C} / \mathrm{min}$ and a frequency of $1 \mathrm{~Hz}$, under a nitrogen atmosphere. The size of the films was $10 \mathrm{~mm} \times$ $10 \mathrm{~mm} \times 0.5 \mathrm{~mm}$ for the tension attachment.

The cross-section SEM micrographs of the samples were obtained with a Quanta 200 electron microscope (from FEI Company), working at $20 \mathrm{kV}$ in low vacuum mode, without any coating. The surface images of the samples were obtained with a Verios G4 UC electron microscope (from Thermo Fisher Scientific, Brno-Černovice, Czech Republic) (SEM), working in high vacuum mode at $5 \mathrm{kV}$, after applying a $10 \mathrm{~nm}$ Platinum layer with the Leica EM ACE200 coating system (from Leica Microsystems). In both cases, the samples were fixed on aluminum stubs with double-adhesive carbon tape. The average pore size was calculated using Image $\mathbf{J}$ software. Contact angle measurements have been performed by using a goniometer KSV Instruments LTD CAM 101 Optical Video Contact Angle System (Helsinki, Finland). Contact angles were measured using the sessile-drop technique at room temperature and a KSV CAM 101 goniometer, equipped with a special optical system and a CCD camera connected to a computer to capture and analyze the contact angle (five measurements for each surface). A drop of liquid $(\approx 1 \mu 1)$ was placed, with a Hamilton syringe, on a specially prepared plate of substratum, and the image was sent via the CCD camera to the computer for analysis. The measurements were carried out at $25^{\circ} \mathrm{C}$ and $65 \%$ relative humidity.

A homemade membrane permeation test apparatus was used to measure the water/ethanol flux of the membrane. A membrane was placed into the filtration cell (effective area of $0.5026 \mathrm{~cm}^{2}$ ), and the applied pressure was controlled at 1.5 bar by air gas. All tests were carried out at room temperature. The flux or permeation rate is defined as the volume flowing through the membrane per unit area and time. The equation that describes the permeate flux $J\left[1 \cdot \mathrm{m}^{-2} \cdot \mathrm{h}^{-1}\right]$ is (Equation (1)):

$$
J=\frac{V}{A \Delta t}
$$

where $V$ is the volume of water/ethanol [1], A the membrane surface area $\left[\mathrm{m}^{2}\right]$, and $\Delta \mathrm{t}$ the permeation time $[\mathrm{h}]$.

The water/isopropyl alcohol (IPA)/ethanol (EtOH) absorption property of the samples was tested by their immersion in water/alcohol for $2 \mathrm{~h}$ at $25^{\circ} \mathrm{C}$. The membrane in a wet state was weighed in an electronic balance after carefully wiping the surface with a clean tissue, $W_{\mathrm{w}}$. This wet membrane was dried in an oven at $50-60^{\circ} \mathrm{C}$ for $24 \mathrm{~h}$. Then, the membrane was weighed again in a dry state, $W_{\mathrm{d}}$. The average value of three measurements was accounted for each sample. The water/alcohol uptake ratios were calculated by Equation (2) [32], and the data are presented in Table 3:

$$
\text { Water/alcohol uptake }[\%]=\frac{W_{\mathrm{w}}-W_{\mathrm{d}}}{W_{\mathrm{d}}} \cdot 100
$$

The antimicrobial activity screening of the samples (M5, M1, M3, and M4) was determined by disk diffusion assay against the following bacterial and yeast strains: Staphylococcus aureus ATCC 25923, Escherichia coli ATCC 25922, Pseudomonas aeruginosa ATCC 27853, Klebsiella pneumoniae ATCC 10031, Candida albicans ATCC 10231 and Candida glabrata ATCC2001. All microorganisms were stored at $-80^{\circ} \mathrm{C}$ in $20 \%$ glycerol. The bacterial strains were refreshed in trypticase soy broth (TSB), and the yeast strains (C. albicans and C. glabrata) were refreshed on Sabouraud dextrose broth (SDB) at the same temperature. K. pneumoniae was refreshed in nutrient broth (NB). Microbial suspensions were prepared with these cultures in sterile solution to obtain turbidity optically comparable to that of $0.5 \mathrm{McFarland}$ standards. Volumes of $0.2 \mathrm{ml}$ from each inoculum were spread onto trypticase soy agar (TSA), nutrient agar (NA), and Sabouraud dextrose agar (SDA) plates, and the sterilized samples were placed on the inoculated plates. In order to evaluate the antimicrobial properties, the growth inhibition was measured under standard conditions after $24 \mathrm{~h}$ of incubation at $36 \pm 1^{\circ} \mathrm{C}$. All tests were carried out in triplicate to verify the results. After incubation, the diameters of inhibition zones were measured by using Image J software (University of Wisconsin, Madison, WI, USA). All data were expressed as the mean \pm standard deviation (SD) by using XLSTAT software. After incubation, the samples were removed from the plates, inactivated at $121^{\circ} \mathrm{C}$ for $20 \mathrm{~min}$, and analyzed for 
surface and structure modifications. These samples were afterward analyzed for structural (FTIR) and morphological (SEM) modifications.

\section{Results and discussion}

\subsection{ATR-FT-IR spectra analysis}

The structure of the films/membrane shown in Figure 1 was confirmed using ATR-FTIR spectroscopy. The IR spectra (Figure 2) revealed the absorption bands at about $1776 \mathrm{~cm}^{-1}$ attributed to the existence of DA adduct resulted from the chemical reaction between furan and maleimide groups and at $1190 \mathrm{~cm}^{-1}$ assigned to $v_{\mathrm{C}-\mathrm{N}-\mathrm{C}}$ from cycloadduct [24]. The strong absorption band of the $>\mathrm{C}=\mathrm{O}$ stretching shifted from $1730 \mathrm{~cm}^{-1}$ (in M5) to $1710-1713 \mathrm{~cm}^{-1}$ (in $\mathbf{M}(\mathbf{1}, \mathbf{3})$ ) due to the interaction between $\mathbf{P V F}$ and maleimide, and new absorption bands appeared at

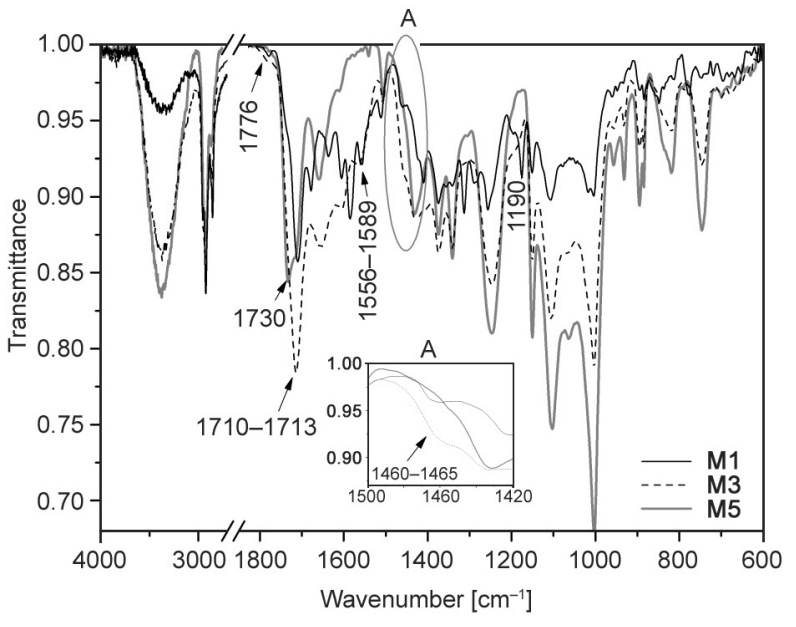

Figure 2. FTIR spectra of membranes.

1556-1589, 1460-1465, $1409 \mathrm{~cm}^{-1}$ for $\mathbf{M}(\mathbf{1}, \mathbf{3})$ attributed to the nonpolymeric trialkyltin carboxylate in the solid-state ( $\left.v_{\mathrm{COO} \text { asym, }} v_{\mathrm{COO}} \mathrm{sym}\right)$ [30].

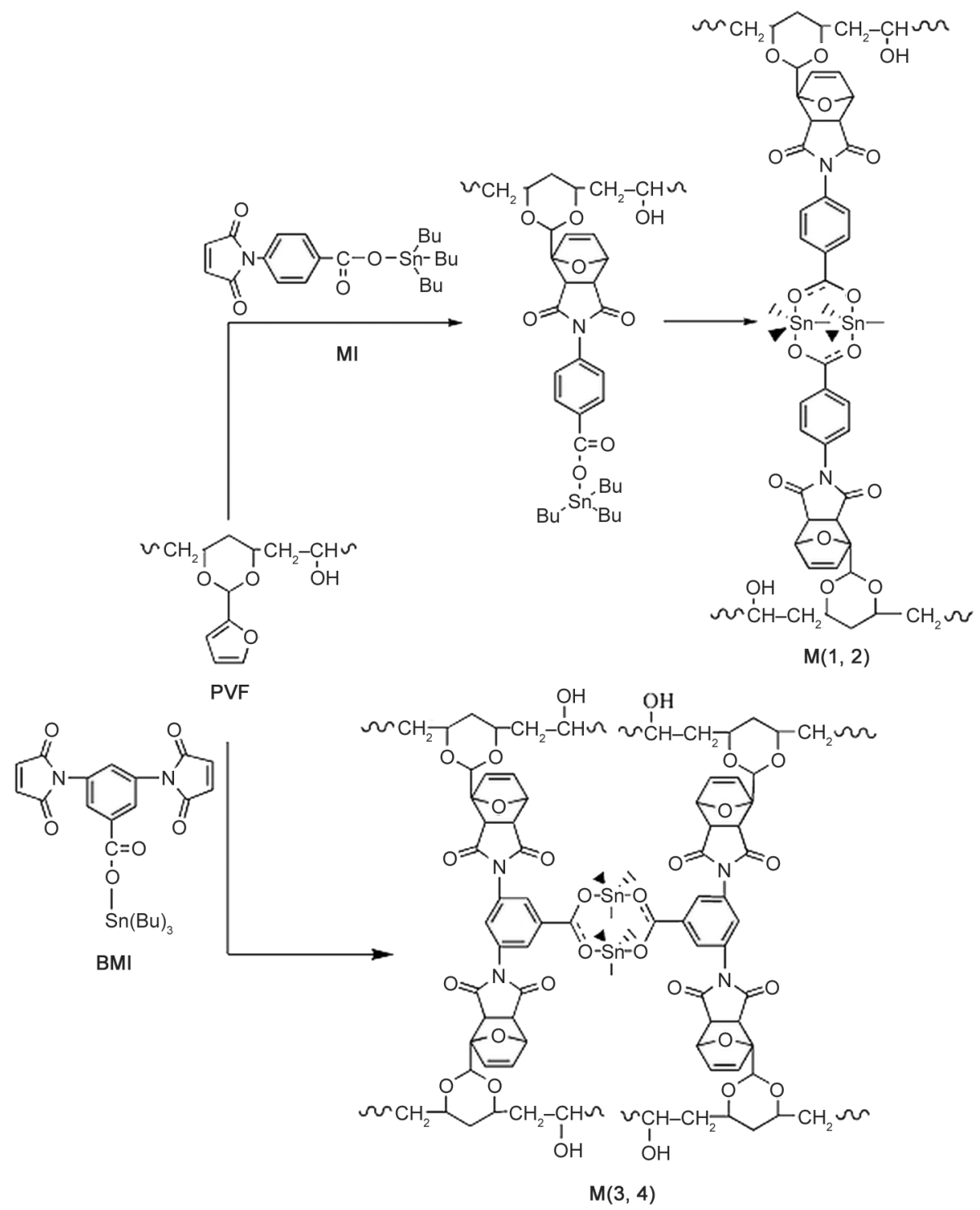

Figure 1. Synthetic scheme for the preparation of membranes/films M(1-4). 


\subsection{Thermal analysis of membranes}

The TGA measurements were conducted to investigate the thermal stability of the M5 membrane and $\mathbf{M}(2,4)$ films, and the data are presented in Table 1. Analysis of TG/DTG curves corresponding to these samples evidenced the presence of two or three stages of thermal degradation (Figure 3). First, all samples lost up to $2.6 \%$ mass in the temperature range of $75-133^{\circ} \mathrm{C}$, assigned to physical dehydration. The films based on maleimide presented three stages of decomposition, whereas the ones based on bismaleimide had only two stages of decomposition. The first degradation stage occurred in the range of $133-290^{\circ} \mathrm{C}$ with a mass loss of $4.13-22 \%$ and may be attributed to the residual solvents in the polymers. The second stage of degradation that took place between $252-390{ }^{\circ} \mathrm{C}$ was accompanied by a mass loss of $28-48.3 \%$, and it was similar to that of networks based on PVF and multifunctional maleimide compounds [24]. Besides the elimination of water molecules from PVF chains and acetic acid from acetate groups [24], the decomposition of tributyltin carboxylate groups could also take place during this stage [30]. The third stage of decomposition indicated the breakdown of the polymer chain. As can be observed in Table 1, the introduction of maleimide/ bismaleimide considerably increased the char yield of the polymers.

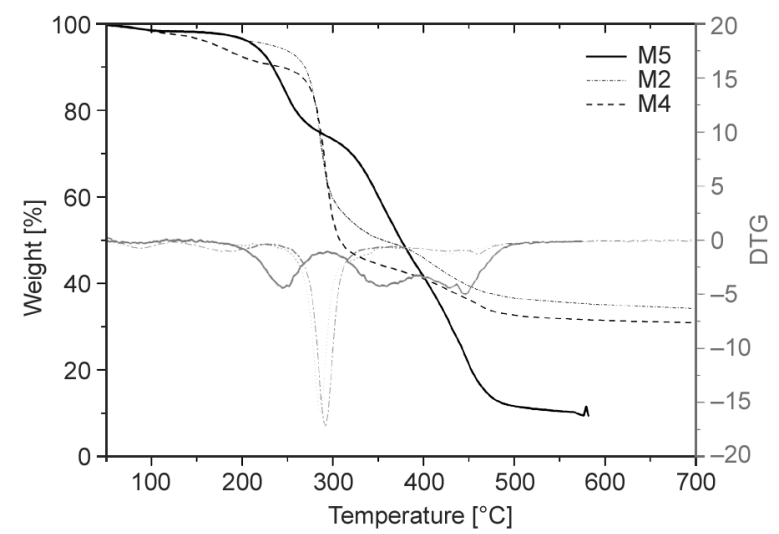

Figure 3. TGA (black curves) and DTG (grey curves) curves of the samples $\mathbf{M}(\mathbf{2}, \mathbf{4}, \mathbf{5})$.

\subsection{Dynamic mechanical analysis}

In addition to the TGA study, DMA was also employed to examine the thermal behavior of the polymer networks. The storage modulus $\left(E^{\prime}\right)$ and dissipation factor $(\tan \delta)$ versus time curves of networks based on PVF and $\mathbf{M}(\mathbf{1}, \mathbf{3})$ membranes are plotted against temperature (Figure 4). DMA curves of the membranes M1 and M3 show a single drop attributed to retro-Diels-Alder reaction and varied between 110 and $123^{\circ} \mathrm{C}$.

As can be observed in Figure 4 and Table 2, by reaction of PVF with MI/BMI compounds, E' was reduced from 1728 to 256 (for M1) and $51 \mathrm{MPa}$ (for M3), respectively. $E^{\prime}$ of membranes $\mathbf{M 1}$ and $\mathbf{M 3}$ decreased slowly and progressively with temperature, showing a very strong decay in the range temperature of $106-147^{\circ} \mathrm{C}$ for $\mathbf{M 1}$ and $113-157^{\circ} \mathrm{C}$ for M3, respectively. The storage modulus of the polymers at $20^{\circ} \mathrm{C}$ decreased in the order: PVF $>$ M1 $>$ M3. The higher storage modulus at $20^{\circ} \mathrm{C}$ of PVF is explained

Table 2. Dynamic mechanical data of PVF, M1 and M3.

\begin{tabular}{|l|r|c|c|c|}
\hline Sample & \multirow{2}{*}{$\begin{array}{c}\boldsymbol{E}_{20}^{\prime}{ }^{\circ} \mathbf{C} \\
{[\mathbf{M P a}]}\end{array}$} & $\begin{array}{c}\text { Maximum } \boldsymbol{E}^{\prime \prime} \\
{[\mathbf{M P a}]}\end{array}$ & \multicolumn{2}{|c|}{$\tan \delta$ peak } \\
\cline { 4 - 5 } & & & Height & $\begin{array}{c}\text { Temperature } \\
{\left[{ }^{\circ} \mathbf{C}\right]}\end{array}$ \\
\hline PVF & 1728 & 216.00 & $0.77 ; 10.06$ & $100.70 ; 178$ \\
\hline M1 & 256 & 18.93 & 1.23 & 159 \\
\hline M3 & 51 & 6.86 & $1.96 ; 3.91$ & $138 ; 162$ \\
\hline
\end{tabular}

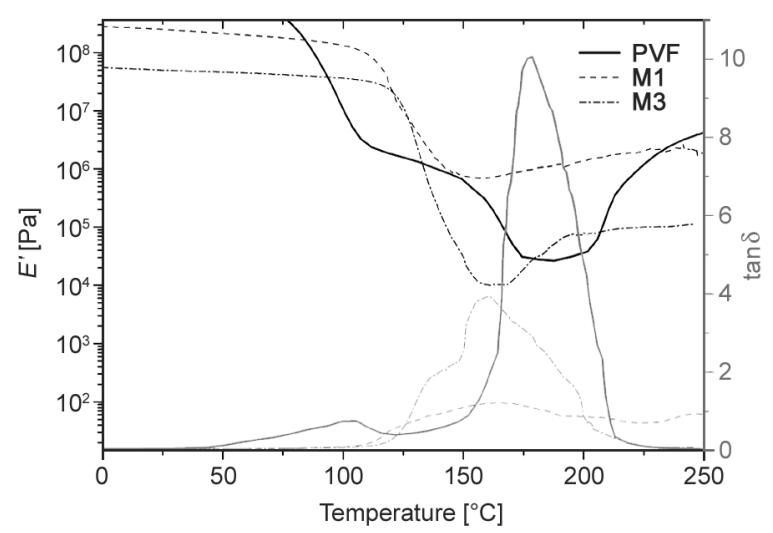

Figure 4. The storage modulus, and dissipation factor $\tan \delta$ profiles of PVF, M1, and M3 samples.

Table 1. Thermogravimetric data of the $\mathbf{M}(\mathbf{2}, \mathbf{4}, \mathbf{5})$ membranes.

\begin{tabular}{|c|c|c|c|c|}
\hline \multirow{2}{*}{ Sample } & \multicolumn{3}{|c|}{$\begin{array}{c}\text { Decomposition temperature } \\
{\left[{ }^{\circ} \mathbf{C}\right] / \text { weight loss [\%] }}\end{array}$} & $\begin{array}{c}\boldsymbol{Y}_{\mathbf{c}} \\
\text { [\%] }\end{array}$ \\
\cline { 2 - 5 } & stage I & stage II & $(405-435) / 4.93$ & 34 \\
\hline M2 & $(163-223) / 4.13$ & $(255-325) / 34.70$ & - & 30.82 \\
\hline M4 & $(140-212) / 7.55$ & $(268-312) / 48.30$ & $(390-500) / 37$ & 9 \\
\hline M5 & $(200-290) / 22$ & $(300-390) / 28$ & stage III & \\
\hline
\end{tabular}

${ }^{\mathrm{a}} \mathrm{Char}$ yield at $700^{\circ} \mathrm{C}$, except $\mathbf{M 5}\left(600^{\circ} \mathrm{C}\right)$ 
by the degree of crystallinity and the physical crosslinks (formation of hydrogen bonds between the $\mathrm{OH}$ groups of PVF), which decreased as temperature increased, its value is lower than that of the other membranes, as the hydrogen bonds disappeared and thus the mobility of the macromolecular chains increased [24]. The membranes M1 and M3 have much lower storage moduli since the introduction of maleimide/bismaleimide increased the distance between the chains, giving them higher flexibility. Loss modulus $\left(E^{\prime \prime}\right)$ represents the result of the viscous behavior of the polymers (films), and it is also a measure of the dissipated energy as heat. Like the storage modulus, $E^{\prime \prime}$ decreased (from $216 \mathrm{MPa}$ for PVF to $19.93 / 6.86$ for M1/M3, respectively) and moved to much higher temperature values (from $66.3^{\circ} \mathrm{C}$ in PVF to $116^{\circ} \mathrm{C}$ in $\mathbf{M 1}$ and $123^{\circ} \mathrm{C}$ in M3). After this maximum value of the loss modulus, the viscosity decreased as the temperature increased. The shape of $\tan \delta$ plots of membranes showed a broad bimodal maximum between 100 and $178^{\circ} \mathrm{C}$, indicating the presence of two relaxation phenomena. The higher value of $\tan \delta$ in membrane M3 (3.91) compared with M1 (1.23) indicated a high degree of polymer chain mobility.

\subsection{Morphology of the membranes}

The SEM micrographs sustained the fact that the samples had a high porosity, with almost spherical pores distributed evenly inside the membranes, both on the surface and in cross-section. As shown in Figure 5a-5c representing the cross-section SEM micrographs, while M5 and M1 had a similar average pore size of around 2.5 and $2 \mu \mathrm{m}$, respectively, M3 had a much smaller pore size of around $425 \mathrm{~nm}$. The same tendency can be seen on the surface of the membranes in Figure 5d-5f.

On the surface, $\mathbf{M 5}$ showed interpenetrating pores of variable size, whereas M1 appeared to have closed pores on its surface. M3 appeared to have a combination of interpenetrating and closed pores on the surface, which could influence the membrane's performances (such as sorption) as a function of surface roughness. The corresponding polymeric films (M2 and M4) followed the same trend regarding the average size of the pores as in the case of the membranes (Figure 6).

Thus, M2 film (which was obtained with the same maleimide as the M1 membrane) showed a larger average pore size of around $4.7 \mu \mathrm{m}$. Meanwhile, M4 film (which was obtained with the same bismaleimide as M3 membrane) showed a significantly smaller average pore size of around $1.12 \mu \mathrm{m}$. Moreover, the pores of $\mathbf{M} 2$ film had a higher depth than the pores on M4 film, which means that M2 film had a higher surface roughness. In both cases, the pores were evenly distributed on each polymeric film surface.

\subsection{Solvent uptake ratio}

The change in surface hydrophilicity might induce the modification in the water/alcohol absorption of membranes. The water/alcohol content of membranes depends on the cross-linking. The wettability performance of the obtained membranes was associated with their chemical structure. As can be observed from Table 3, the solvent uptake ratio in water or alcohol (EtOH, IPA) of membranes M1 and M3 decreased compared to that of M5, but the water values were lower than those of IPA and EtOH. From the surface morphology, it is clear that the membrane based on bismaleimide (M3) showed a combination of interpenetrating and closed pores on the surface, which led to an increase in solvent uptake. The membrane-based on maleimide compound (M1) had the lowest water/alcohol uptake ratio due to a higher degree of cross-linking; this fact was confirmed by the increase in hydrophobicity (having a water contact angle of $119.54^{\circ}$ ) and DMA data.

The permeate flux was measured for the M3 microporous membrane. As shown in Figure 7, the permeate flux was steady and observed to be approximately $19.26 \mathrm{l} \cdot \mathrm{m}^{-2} \cdot \mathrm{h}^{-1}$ for water and $5.572 \mathrm{l} \cdot \mathrm{m}^{-2} \cdot \mathrm{h}^{-1}$ for ethanol (EtOH). For cross-linked membrane M3, the highest solvent permeance was measured for water, which is the solvent with the lowest viscosity $(0.00089 \mathrm{~Pa} \cdot \mathrm{s})[33]$. Moreover, the interactions between the solvent and the membrane could lead to swelling, affecting the permeate flux. As can be seen from Table 3, the IPA uptake ratio for M3 was much higher compared with the ones of water/EtOH, which led to swelling of the membrane. This may be the reason why the permeate flux of IPA could not be measured.

\subsection{Antimicrobial activity}

The antimicrobial activity screening of the samples (M1, M3, M4, and M5) was determined by disk diffusion assay against the following bacterial and yeast strains: Staphylococcus aureus ATCC 25923, Escherichia coli ATCC 25922, Pseudomonas aeruginosa 


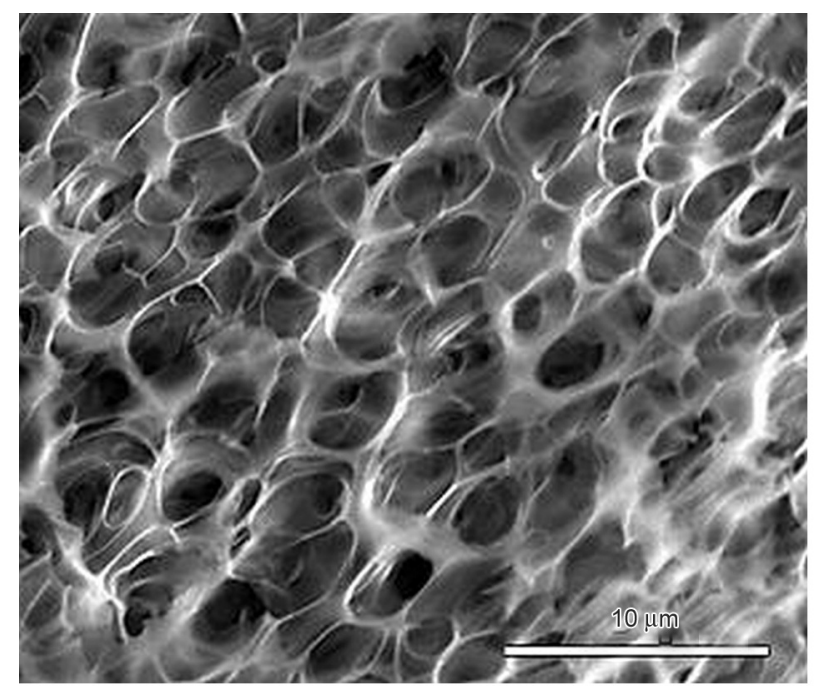

a)

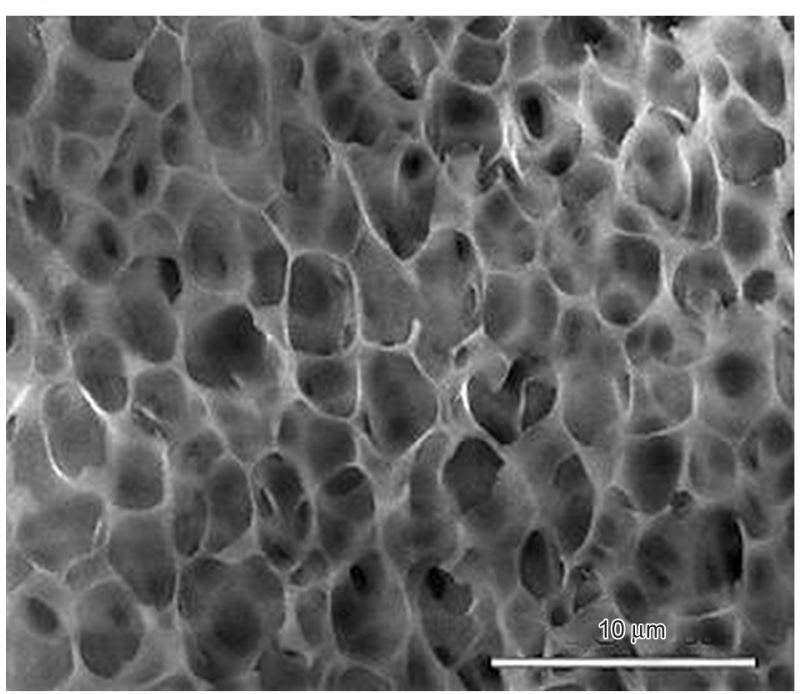

c)

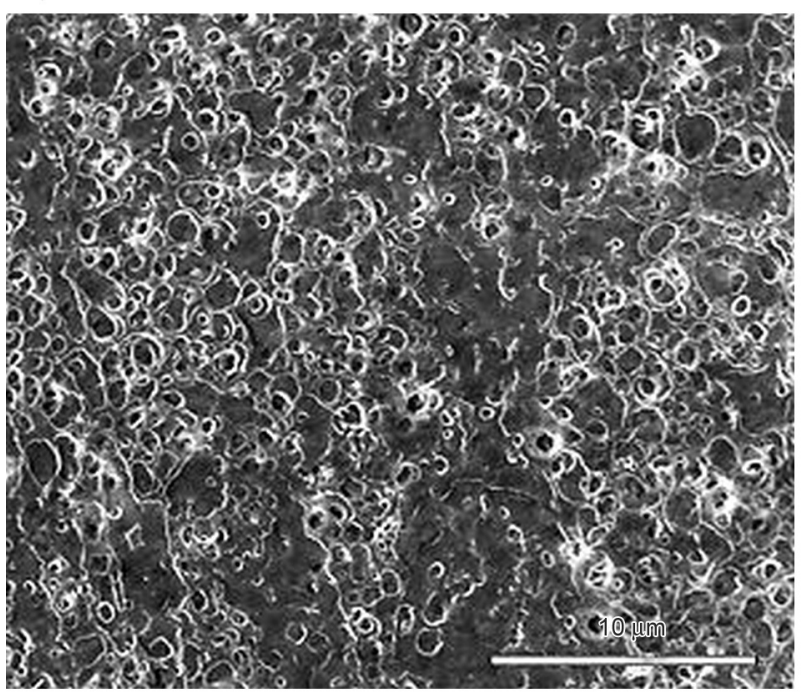

e)

Figure 5. SEM images of membranes in cross-sections: M1 (a), M3 (b), M5 (c) and on the surface: M1 (d), M3 (e), M5 (f).

ATCC 27853, Klebsiella pneumoniae ATCC 10031, Candida albicans ATCC 10231 and Candida glabrata ATCC2001. The tested samples (M1, M3, and M4)
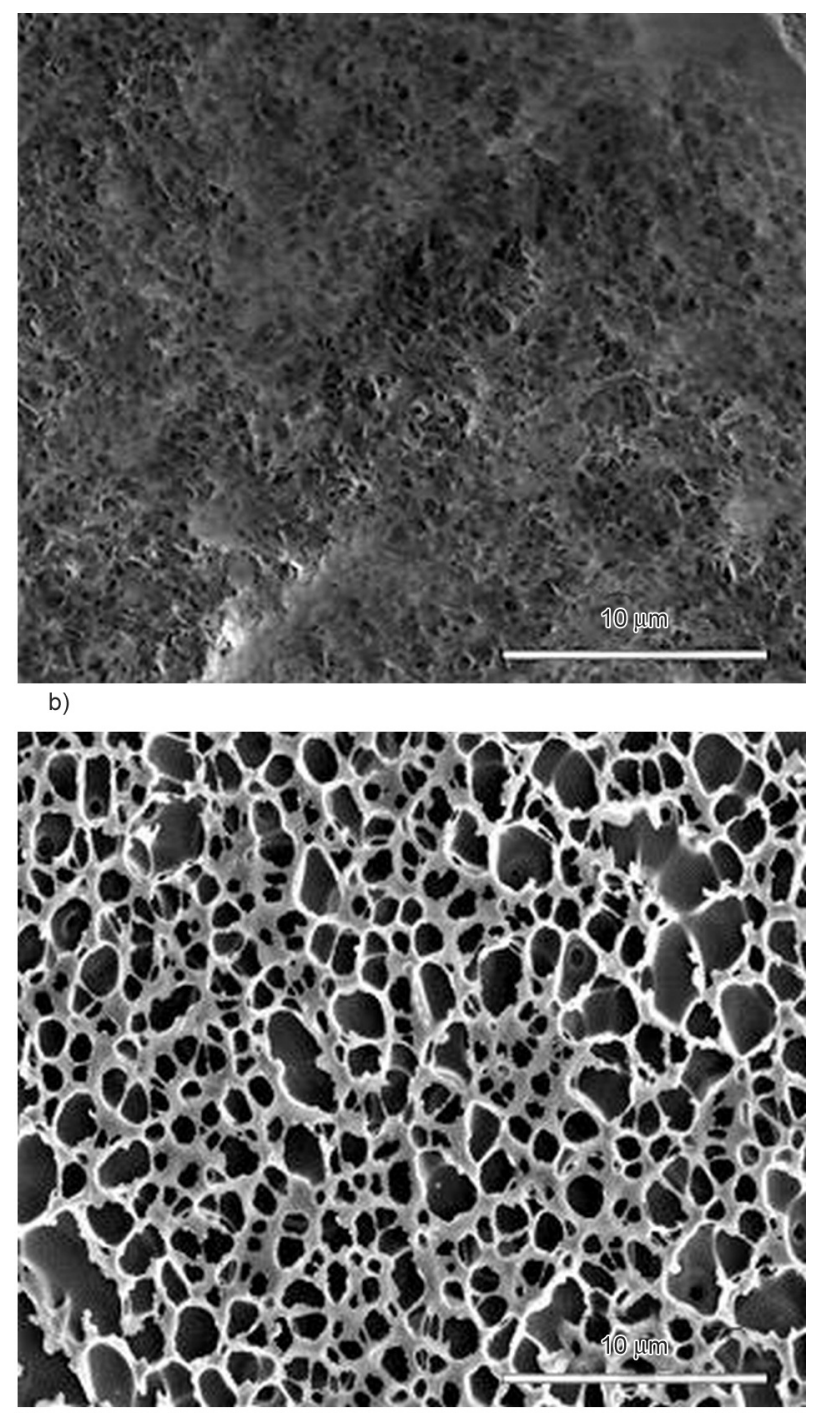

d)

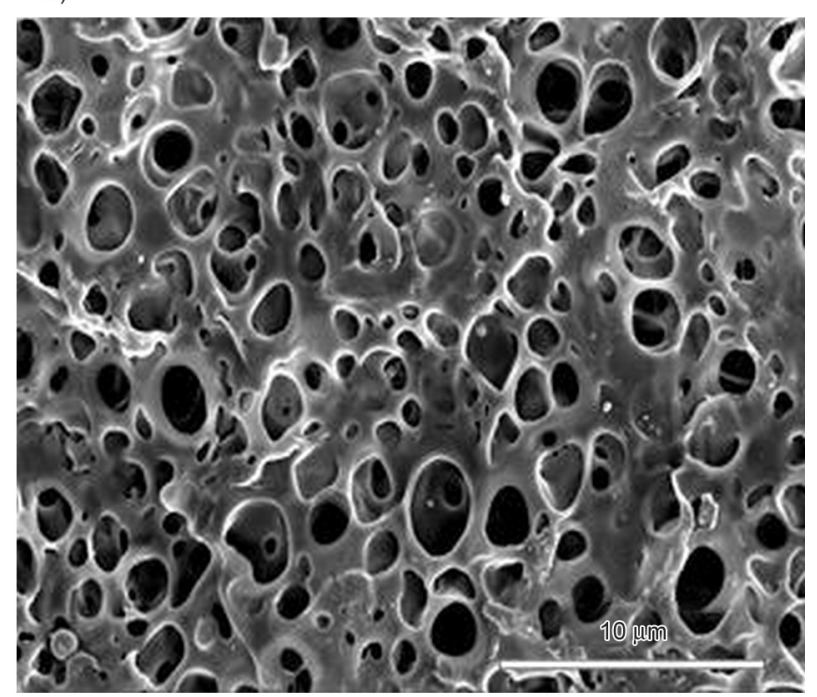

were efficient against the yeast strains represented by C. albicans (Figure 8e) and C. glabrata (Figure 8f) and against the Gram-positive strain represented by 


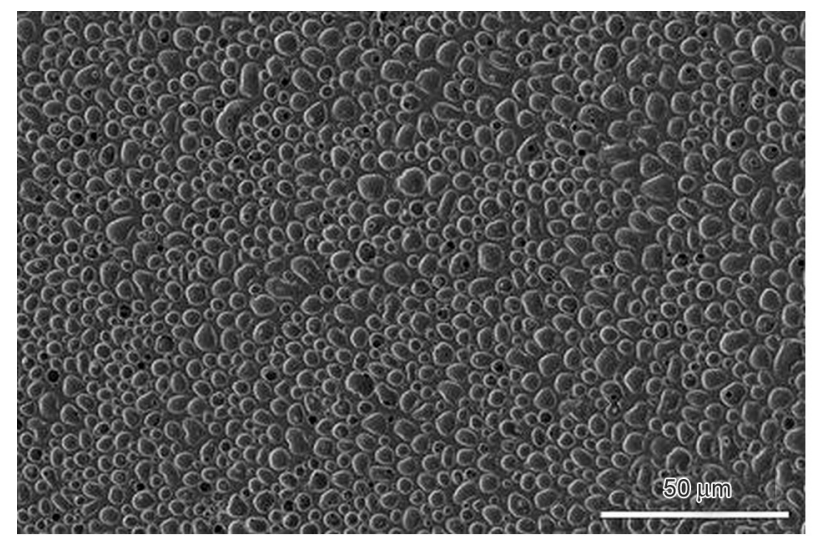

a)

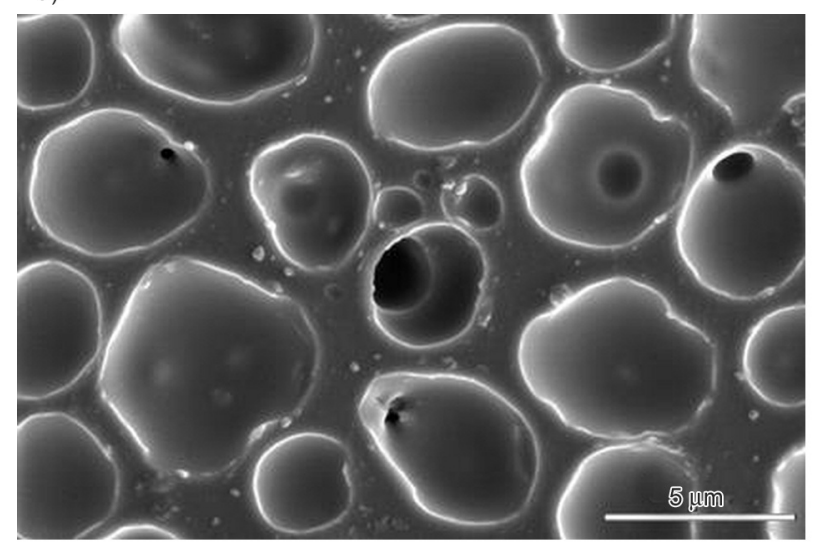

c)

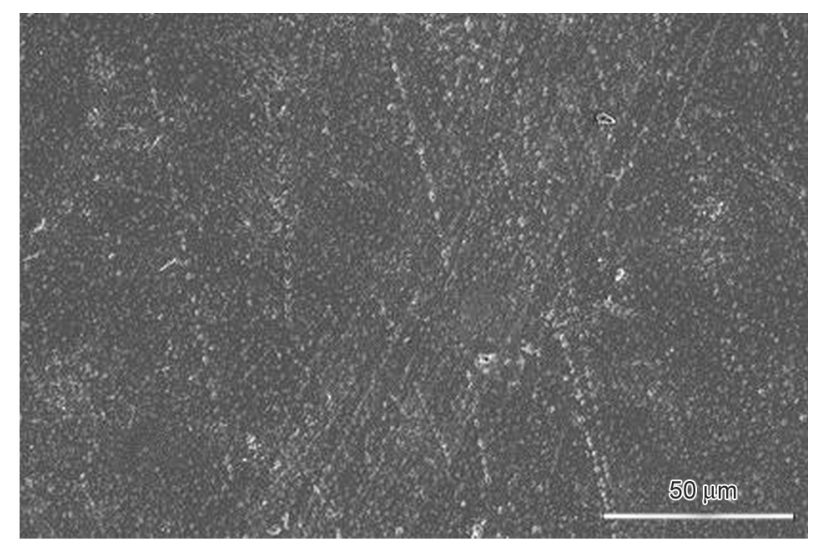

b)

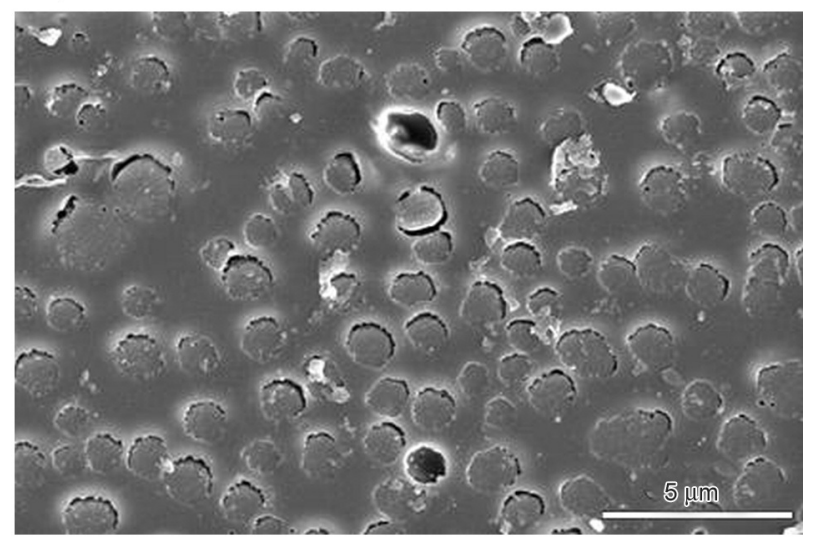

Figure 6. SEM micrographs of the polymeric film surfaces of M(2, 4): overview: M2 (a), M4 (b), and detail: M2 (c), M4 (d).

S. aureus (Figure 8a). Among these results, it can be noticed that the sample encoded M4 had the greater

Table 3. Water/alcohol uptake and water contact angle of $\mathbf{M}(1,3,5)$.

\begin{tabular}{|c|c|c|c|c|}
\hline \multirow[t]{2}{*}{ Sample } & \multicolumn{3}{|c|}{$\begin{array}{c}\text { Solvent uptake ratio of membranes } \\
{[\%]}\end{array}$} & \multirow{2}{*}{$\begin{array}{c}\text { Water } \\
\text { contact angle } \\
{\left[{ }^{\circ}\right]}\end{array}$} \\
\hline & Water & IPA & EtOH & \\
\hline M1 & 51.44 & 111.53 & 42.55 & 119.54 \\
\hline M3 & 188.95 & 226.72 & 196.72 & 89.65 \\
\hline M5 & 215.90 & 266.15 & 242.57 & 77.40 \\
\hline
\end{tabular}

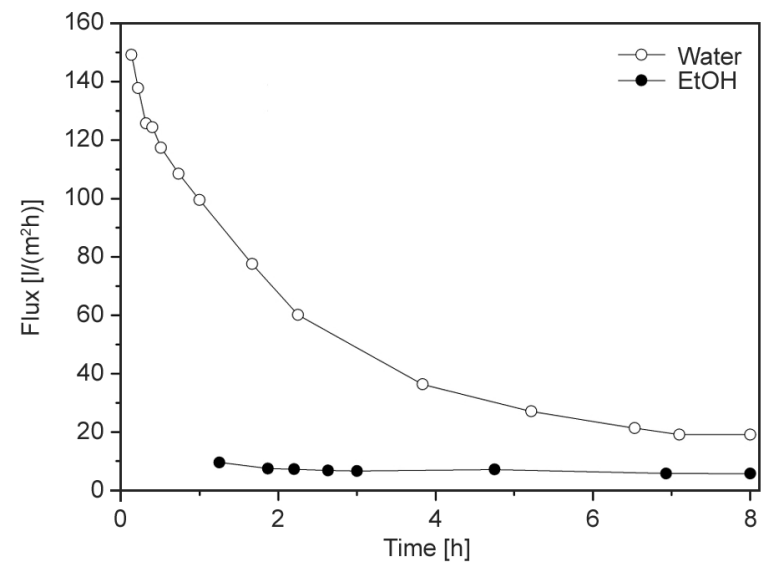

Figure 7. Permeate flux of M3. activity against the opportunistic pathogens (as presented in Table 4). In the case of C. albicans, the samples M3, M4, and M1 had almost the same efficiency. The control sample (M5) had a slightly antifungal activity only against $C$. albicans and did not have activity against the other strains, including C. glabrata. The samples did not present antimicrobial activity against the bacterial strains represented by E. coli, P. aeruginosa, and $K$. pneumoniae (Figure 8b-8d), probably due to their Gram-negative cell wall composition, distinctive rod-shaped, extracellular matrix, and due to their multicomponent efflux pumps, which are expelling toxic molecules and usually confer them drug resistance [34]. It is also known that metal complexes are responsible for microorganism's growth reduction by inhibiting the synthesis of proteins as well as interrupting the process of respiration in microorganisms, both bacterial and fungal strains [35]. Literature stipulates that tributyltin compounds have antibacterial activity against Gram-positive bacteria and lower activity or non-activity against Gram-negative bacterial strains [36]. The higher effectiveness of complexes against Grampositive bacteria in comparison with Gram-negative 


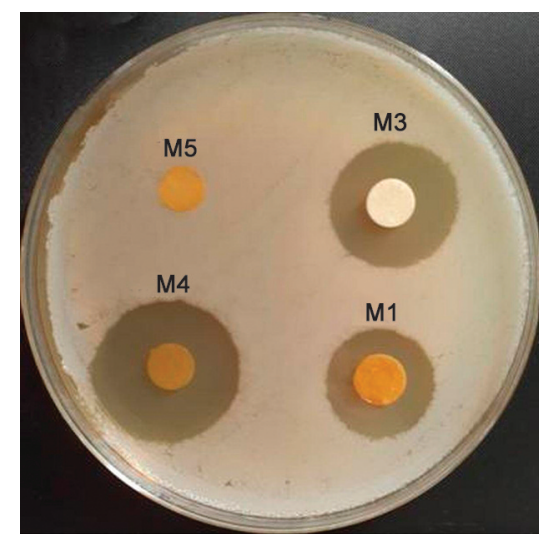

a)

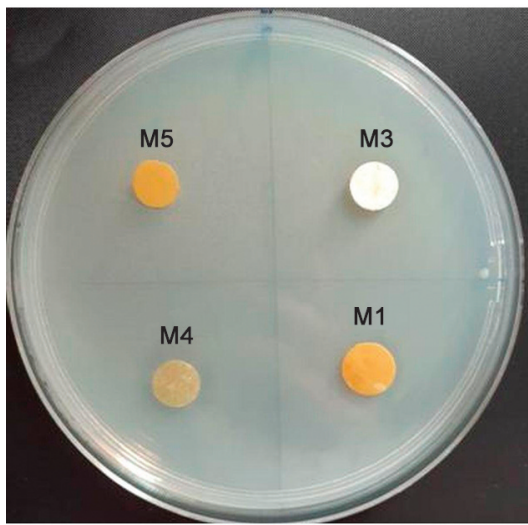

d)

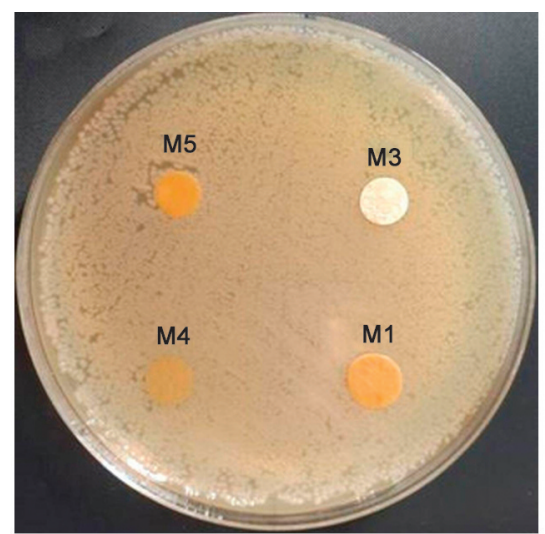

b)

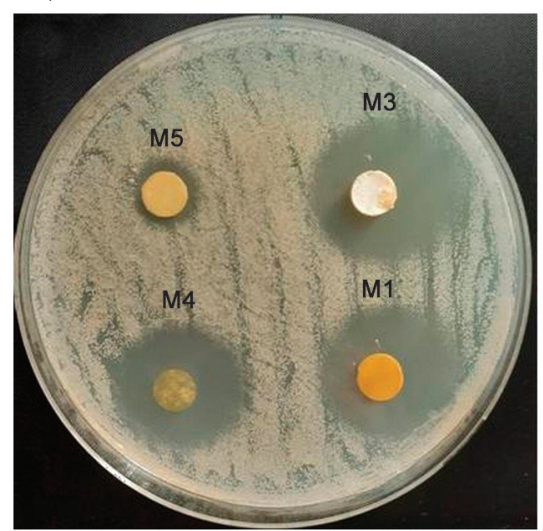

e)

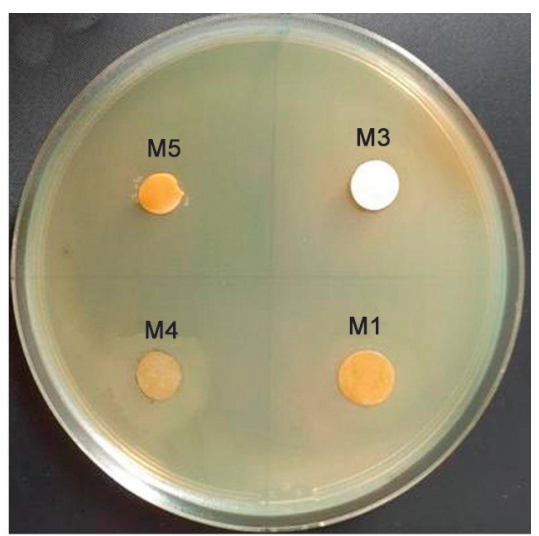

c)

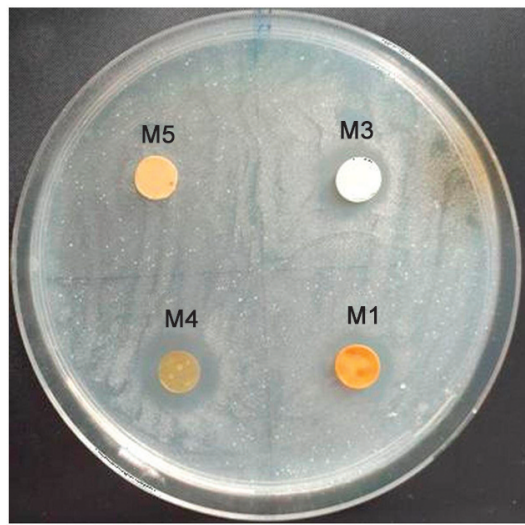

f)

Figure 8. Antimicrobial activity of the tested samples against S. aureus (a), E. coli (b), P. aeruginosa (c), K. pneumoniae (d), C. albicans (e), and C. glabrata (f).

Table 4. Antimicrobial activity $[\mathrm{mm}]$ of the tested samples against the reference strains.

\begin{tabular}{|ll|c|c|c|c|}
\hline \multirow{2}{*}{ Strain } & \multicolumn{4}{c|}{ Inhibition zone } \\
& & & \multicolumn{4}{c|}{ [mm] } & M3 \\
\cline { 3 - 6 } & & M5 & M1 & M3 & - \\
\hline Staphylococcus aureus & ATCC25923 & - & $21.509 \pm 0.868$ & $23.706 \pm 0.665$ & $26.819 \pm 0.723$ \\
\hline Escherichia coli & ATCC25922 & - & - & - & - \\
\hline Pseudomonas aeruginosa & ATCC27853 & - & - & - & - \\
\hline Klebsiella pneumonia & ATCC10031 & - & - & - & $26.364 \pm 0.315$ \\
\hline Candida albicans & ATCC10231 & $12.065 \pm 0.816$ & $25.905 \pm 0.366$ & $27.225 \pm 0.698$ & $19.935 \pm 0.704$ \\
\hline Candida glabrata & ATCC2001 & - & $15.653 \pm 0.977$ & $15.739 \pm 0.311$ & 1 \\
\hline
\end{tabular}

may come from a more simple structure of the cell wall of the former so that tin complexes can easier penetrate into the cells of Gram-positive bacteria. As presented in Figure 9 (FTIR spectra) and Figure 10 (SEM), the samples not only proved remarkable antimicrobial activity but also did not allowed the adherence of the bacterial/fungal cells to their surfaces when compared with the control (M5 vs. M3 and M4). As can be seen from Figure 9, the IR spectra of samples M3 and M4 (which did not allow the adherence of the bacterial/fungal cells to their surfaces) did not present structural modifications, while $\mathbf{M 5}$ incubated with $S$. aureus had structural modifications in

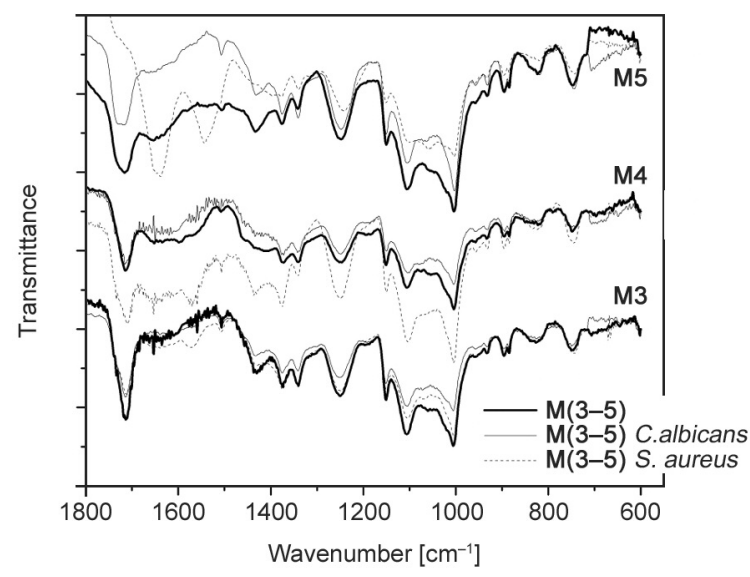

Figure 9. The IR spectra of M3-M5 before and after being incubated with $S$. aureus and C. albicans. 

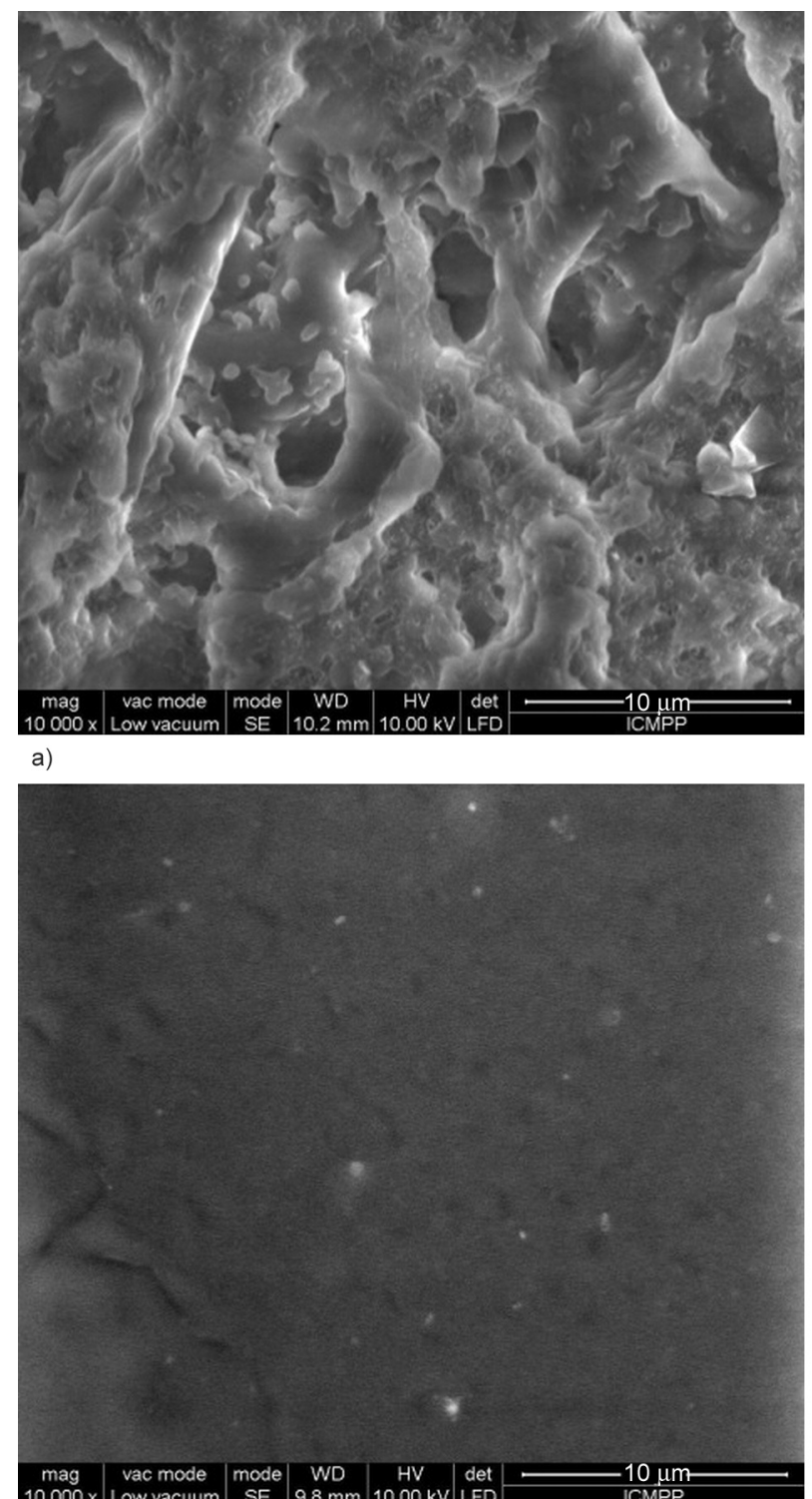

c)

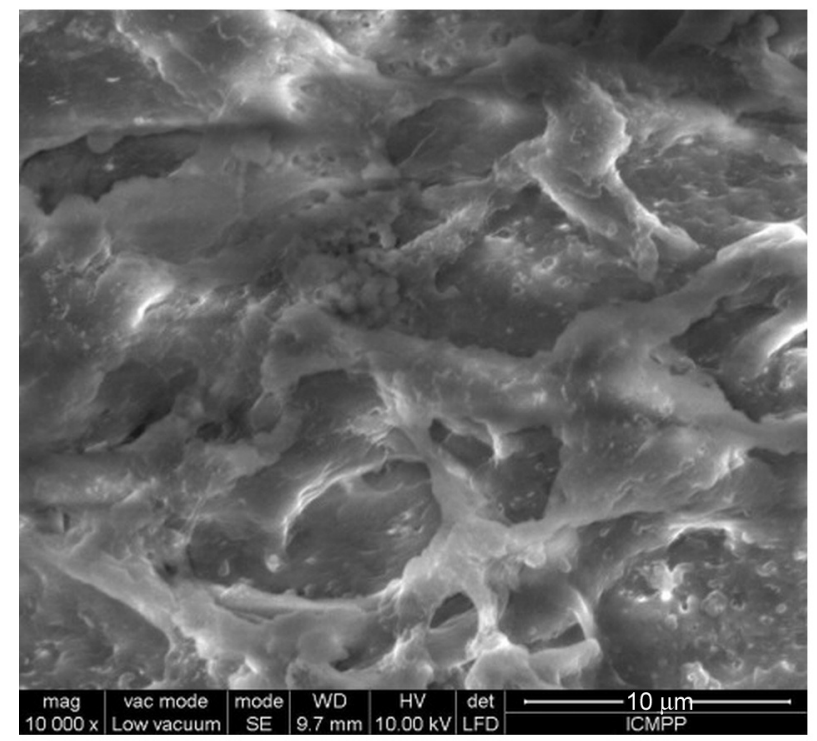

e)

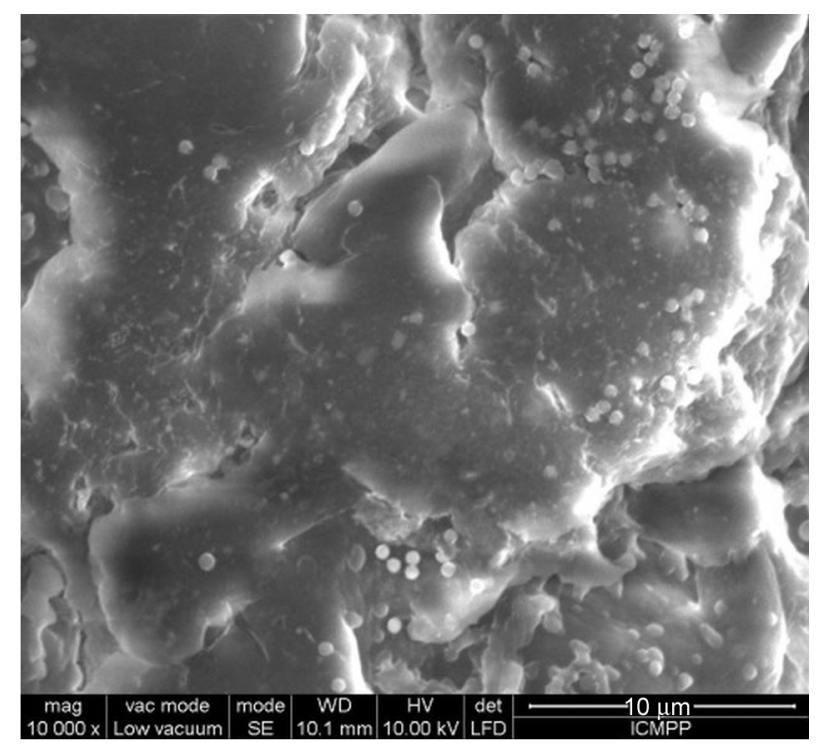

b)

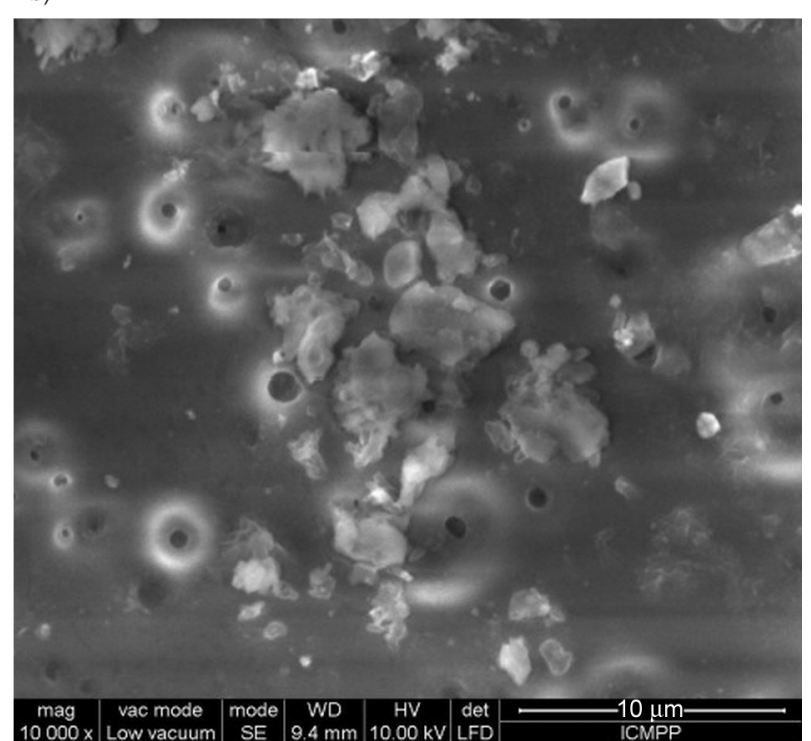

d)

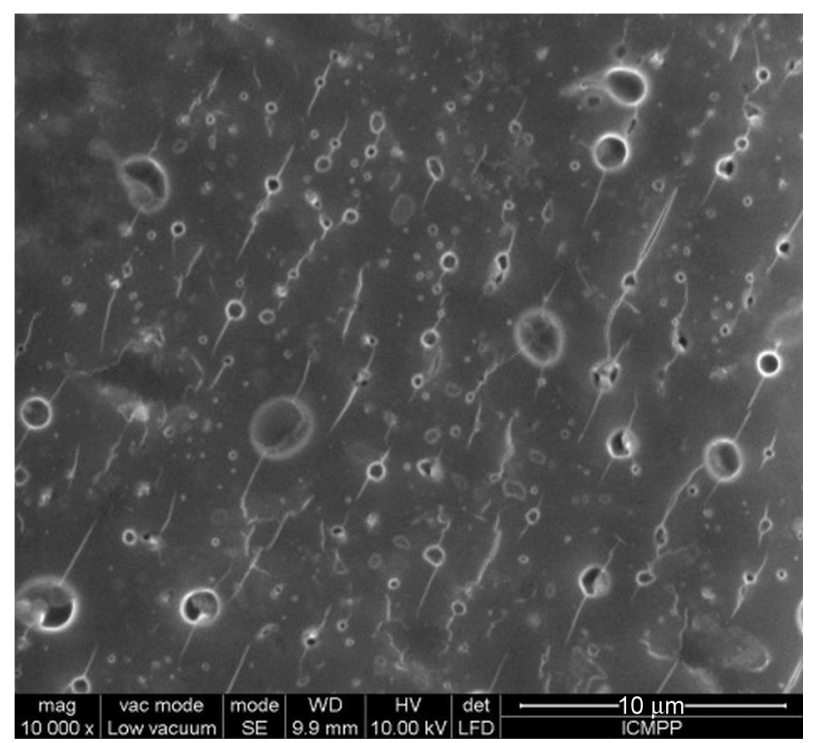

f)

Figure 10. SEM micrographs of the polymeric film surface after being incubated with S. aureus M5 (a), M3 (b) and M4 (c) and C. albicans: M5 (d), M3 (e) and M4 (f). 
the IR spectrum (due to the fact that did not present any antimicrobial activity).

M5 incubated with the reference strains presented a well-developed biofilm and an organic adherence, whereas sample M3 presented only a few cells on its surface, and M4 did not present any antimicrobial adherence proving their antimicrobial and anti-adherence properties (Figure 10). The morphological results were sustained by the structure analysis as mentioned above.

The slightly lower antimicrobial activity of $\mathbf{M 1}$ compared with M3 and M4 could be attributed to the reduced microbial contact due to the higher surface hydrophobicity of this membrane deriving from its higher degree of cross-linking [37].

\section{Conclusions}

In this work, new porous membranes or films based on PVF and maleimide (maleimide and bismaleimide) compounds containing tributyltin groups were prepared by Diels-Alder reactions using different methods.

The FT-IR spectroscopy data confirmed the structures of the polymers obtained. TGA measurements showed a slight decrease in thermal stability of the membranes based on maleimide compounds compared to membranes based on PVF (M5). DMA and water/alcohol uptake ratio measurements highlighted the higher rigidity of the M1 membrane compared to M3. SEM data illustrated that the membrane based on maleimide (M1) had a similar average pore size of around 2.5 and $2 \mu \mathrm{m}$ in M5 (PVF) and had closed pores on its surface while the membrane based on bismaleimide (M3) appeared to have a combination of interpenetrating and closed pores on the surface and had a much smaller pore size of around $425 \mathrm{~nm}$. The corresponding polymeric films (M2 and M4) followed the same trend regarding the average size of the pores as in the case of the membranes $(4.7 \mu \mathrm{m}$ for M2 and $1.12 \mu \mathrm{m}$ for M4). Concerning solvent uptake and permeate flux, it was found that an increase in the solvent viscosity led to a decrease in permeate flux. In our case, M3 showed the best results.

In terms of antimicrobial activity, the membranes/ film M1, M3, and M4 were efficient against the yeast strains represented by $C$. albicans, $C$. glabrata and against the Gram-positive strain represented by S. aureus but did not present antimicrobial activity against the bacterial strains represented by E. coli, $P$. aeruginosa, and $K$. pneumonia. The samples M3 and M4 not only proved remarkable antimicrobial activity but also did not allow the adherence of the bacterial/fungal cells to their surfaces when compared with the control (M5).

To summarize, the membrane-based on bismaleimide presented the best properties (solvent uptake, permeate flux, antimicrobial activity).

\section{References}

[1] Finch C. A.: Polyvinyl alcohol-developments. Wiley, New York (1992).

[2] Moulay S.: Review: Poly(vinyl alcohol) functionalizations and applications. Polymer-Plastics Technology and Engineering, 54, 1289-1319 (2015).

https://doi.org/10.1080/03602559.2015.1021487

[3] Bolto B., Tran T., Hoang M., Xie Z.: Crosslinked poly(vinyl alcohol) membranes. Progress in Polymer Science, 34, 969-981 (2009).

https://doi.org/10.1016/j.progpolymsci.2009.05.003

[4] Wang Y., Hsieh Y-L.: Crosslinking of polyvinyl alcohol (PVA) fibrous membranes with glutaraldehyde and PEG diacylchloride. Journal of Applied Polymer Science, 116, 3249-3255 (2010).

https://doi.org/10.1002/app.31750

[5] Park J-S., Park J-W., Ruckenstein E.: On the viscoelastic properties of poly(vinyl alcohol) and chemically crosslinked poly(vinyl alcohol). Journal of Applied Polymer Science, 82, 1816-1823 (2001).

https://doi.org/10.1002/app.2023

[6] Figueiredo K. C. S., Alves T. L. M., Borges C. P.: Poly(vinyl alcohol) films crosslinked by glutaraldehyde under mild conditions. Journal of Applied Polymer Science, 111, 3074-3080 (2009).

https://doi.org/10.1002/app.29263

[7] Xu G. G., Yang C. Q., Deng Y.: Combination of bifunctional aldehydes and poly(vinyl alcohol) as the crosslinking systems to improve paper wet strength. Journal of Applied Polymer Science, B, 1673-1680 (2004). https://doi.org/10.1002/app.20593

[8] Rhim J-W., Yeom C-K., Kim S-W.: Modification of poly(vinyl alcohol) membranes using sulfur-succinic acid and its application to pervaporation separation of water-alcohol mixtures. Journal of Applied Polymer Science, 68, 1717-1723 (1998).

https://doi.org/10.1002/(SICI)10974628(19980613)68:11<1717::AID-APP1>3.0.CO;2-M

[9] Giménez V., Mantecón A., Ronda J. C., Cádiz V.: Poly(vinyl alcohol) modified with carboxylic acid anhydrides: Crosslinking through carboxylic groups. Journal of Applied Polymer Science, 65, 1643-1651 (1997). https://doi.org/10.1002/(SICI)10974628(19970822)65:8\%3C1643::AID-APP20\%3E3.0.CO;2-V 
[10] Giménez V., Mantecón A., Cádiz V.: Crosslinking of poly(vinyl alcohol) using dianhydrides as hardeners. Journal of Applied Polymer Science, 59, 425-431 (1996). https://doi.org/10.1002/(SICI)10974628(19960118)59:3\%3C425::AID-APP6\%3E3.0.CO;2-R

[11] Krumova M., López D., Benavente R., Mijangos C., Pereña J. M.: Effect of crosslinking on the mechanical and thermal properties of poly(vinyl alcohol). Polymer, 41, 9265-9272 (2000). https://doi.org/10.1016/S0032-3861(00)00287-1

[12] Salavagione H. J., Gómez M. A., Martínez G.: Polymeric modification of graphene through esterification of graphite oxide and poly(vinyl alcohol). Macromolecules, 42, 6331-6334 (2009).

https://doi.org/10.1021/ma900845w

[13] Chen J., Li Y., Zhang Y., Zhu Y.: Preparation and characterization of graphene oxide reinforced PVA film with boric acid as crosslinker. Journal of Applied Polymer Science, 132, 42000 (2015).

https://doi.org/10.1002/app.42000

[14] Chuang W-Y., Young T-H., Chiu W-Y., Lin C-Y.: The effect of polymeric additives on the structure and permeability of poly(vinyl alcohol) asymmetric membranes. Polymer, 41, 5633-5641 (2000).

https://doi.org/10.1016/S0032-3861(99)00818-6

[15] Çifci C., Polat Ş.: Polymer-enhanced ultrafiltration of $\mathrm{Fe}(\mathrm{III})$ and $\mathrm{Cu}$ (II) aqueous solutions using poly(vinyl alcohol)-alginic acid/cellulose membranes. Journal of Macromolecular Science Part A: Pure and Applied Chemistry, 46, 682-687 (2009).

https://doi.org/10.1080/10601320902938939

[16] Yuan H., Ren J., Cheng L., Shen L.: Preparation and characterization of a poly(vinyl alcohol)/tetraethoxysilane ultrafiltration membrane by a sol-gel method. Journal of Applied Polymer Science, 130, 4066- 4074 (2013). https://doi.org/10.1002/app.39502

[17] Gohil J. M., Ray P.: Polyvinyl alcohol as the barrier layer in thin film composite nanofiltration membranes: Preparation, characterization, and performance evaluation. Journal of Colloid Interface Science, 338, 121127 (2009). https://doi.org/10.1016/j.jcis.2009.06.020

[18] Lang K., Sourirajan S., Matsuura T., Chowdhury G.: A study on the preparation of polyvinyl alcohol thin-film composite membranes and reverse osmosis testing. Desalination, 104, 185-196 (1996). https://doi.org/10.1016/0011-9164(96)00041-0

[19] Lang K., Matsuura T., Chowdhury G., Sourirajan S.: Preparation and testing of polyvinyl alcohol composite membranes for reverse osmosis. The Canadian Journal of Chemical Engineering, 73, 686-692 (1995). https://doi.org/10.1002/cjce.5450730512

[20] Jeck S., Scharfer P., Kind M.: Water diffusion in poly(vinyl alcohol) membranes: A rigorous analysis of the pervaporation process. Journal of Membrane Science, 417-418, 154-162 (2012).

https://doi.org/10.1016/j.memsci.2012.06.027
[21] Heydari M., Moheb A., Ghiac M., Masoomi M.: Effect of cross-linking time on the thermal and mechanical properties and pervaporation performance of poly(vinyl alcohol) membrane cross-linked with fumaric acid used for dehydration of isopropanol. Journal of Applied Polymer Science, 128, 1640-1651 (2013).

https://doi.org/10.1002/app.38264

[22] Yee K. F., Ong Y. T., Mohamed A. R., Tan S. H.: Novel MWCNT-buckypaper/polyvinyl alcohol asymmetric membrane for dehydration of etherification reaction mixture: Fabrication, characterisation and application. Journal of Membrane Science, 453, 546-555 (2014). https://doi.org/10.1016/j.memsci.2013.11.040

[23] Wang N., Ji S., Li J., Zhang R., Zhang G.: Poly(vinyl alcohol)-graphene oxide nanohybrid 'pore-filling' membrane for pervaporation of toluene/ $n$-heptane mixtures. Journal of Membrane Science, 455, 113-120 (2014). https://doi.org/10.1016/j.memsci.2013.12.023

[24] Gaina C., Ursache O., Gaina V., Buruiana E., Ionita D.: Investigation on the thermal properties of new thermoreversible networks based on poly(vinyl furfural) and multifunctional maleimide compounds. Express Polymer Letters, 6, 129-141 (2012).

https://doi.org/10.3144/expresspolymlett.2012.14

[25] Ursache O., Gaina C., Gaina V., Tudorachi N., Bargan A., Varganici C-D., Rosu D.: Studies on Diels-Alder thermoresponsive networks based on ether-urethane bismaleimide functionalized poly(vinyl alcohol). Journal of Thermal Analyses and Calorimetry, 118, 14711481 (2014).

https://doi.org/10.1007/s10973-014-4041-7

[26] Gaina C., Gaina V., Ionita D.: Functional modification of poly(vinyl alcohol) with maleimide compounds. Polymer Bulletin, 73, 2019-2038 (2016).

https://doi.org/10.1007/s00289-015-1591-1

[27] Ursache O., Gaina V., Gaina C.: Poly(vinyl alcohol)-inorganic hybrid materials with thermocleavable groups. Polymer-Plastics and Technology Engineering, 52, 546-557 (2013).

https://doi.org/10.1080/03602559.2012.762377

[28] Singh K. S., Roy M., Roy S., Ghosh B., Devi N. M., Singh C. B., Mun L. K.: Synthesis, characterization and antimicrobial activities of triorganotin(IV) complexes with azo-azomethine carboxylate ligands: Crystal structure of a tributyltin(IV) and a trimethyltin(IV) complex. Journal of Coordination Chemistry, 70, 361-380 (2017). https://doi.org/10.1080/00958972.2016.1258464

[29] Gaina C., Gaina V., Cristea M.: Poly(urethane-urea) varnishes containing tributyltin groups. Journal of Inorganic and Organometallic Polymers and Materials, 19, 157-164 (2009). https://doi.org/10.1007/s10904-008-9230-z

[30] Gaina C., Gaina V.: Synthesis and characterization of novel organotin carboxylate maleimide monomers and copolymers. Express Polymer Letters, 3, 352-358 (2009).

https://doi.org/10.3144/expresspolymlett.2009.44 
[31] Mikroyannidis J. A.: Thermostable laminating resins based on aromatic diketone bis- and tetramaleimides. Journal of Polymer Science Part A: Polymer Chemistry, 28, 679-691 (1990).

https://doi.org/10.1002/pola.1990.080280317

[32] Zhang J., Xu W-R., Zhang Y., Li W., Hu J., Zheng F., Wu Y.: Liquefied chitin/polyvinyl alcohol based blend membranes: Preparation and characterization and antibacterial activity. Carbohydrate Polymers, 180, 175181 (2018)

https://doi.org/10.1016/j.carbpol.2017.10.014

[33] Chisca S., Duong P. H. H., Emwas A-H., Sougrat R., Nunes S. P.: Crosslinked copolyazoles with a zwitterionic structure for organic solvent resistant membranes. Polymer Chemistry, 6, 543-544 (2015). https://doi.org/10.1039/c4py01293c

[34] Hufnagel D. A., Depas W. H., Chapman M. R.: The biology of the Escherichia coli extracellular matrix. Microbiology Spectrum, 3, MB_0014_2014 (2015).

https://doi.org/10.1128/microbiolspec.MB-0014-2014
[35] Lam P. L., Lee K. K. H., Wong R. S. M., Cheng G. Y M., Bian Z. X., Chui C. H., Gambari R.: Recent advances on topical antimicrobials for skin and soft tissue infections and their safety concerns. Critical Reviews in Microbiology, 44, 40-78 (2018).

https://doi.org/10.1080/1040841X.2017.1313811

[36] Pruchnik H., Lis T., Latocha M., Zielińska A., Ułaszewski S., Pelińska I., Pruchnik F. P.: Butyltin(IV) 2-sulfobenzoates: Synthesis, structural characterization and their cytostatic and antibacterial activities. Journal of Inorganic Biochemistry, 111, 25-32 (2012). https://doi.org/10.1016/j.jinorgbio.2012.02.024

[37] Cheng C-H., Liu H-C., Lin J-C.: Surface modification of polyurethane membrane with various hydrophilic monomers and $N$-halamine: Surface characterization and antimicrobial properties evaluation. Polymers, 13, 2321 (2021).

https://doi.org/10.3390/polym13142321 